\title{
DIAGNOSIS OF DERMATOMYOSITIS TWO MONTHS AFTER COVID-19 INFECTION
}

Raiza Cansian Tuão $0^{1, \star}$, Mariana de Oliveira Macabú ${ }^{1}$, Ketty Lysie Libardi Lira Machado ${ }^{1}$, Estephania Pignaton Naseri¹, Bárbara Ferraço Dalmaso ${ }^{1}$, Gustavo Pinto de Oliveira Gomes ${ }^{1}$, Débora Marques Veghini ${ }^{1}$, Ruben Horst Duque ${ }^{1}$, Lídia Balarini da Silva ${ }^{1}$, Ana Paula Espíndula Gianordoli¹, Bárbara Petronetto Fafá1, Érica Vieira Serrano ${ }^{1}$, Luiza Correa Rodrigues Dalpieroํㅜ, Weider Andrade Tomé ${ }^{1}$, Luiza Vallory Alochio ${ }^{1}$, Paula dos Santos Athayde ${ }^{1}$, Isac Ribeiro Moulaz ${ }^{1}$, Valéria Valim²

1.Universidade Federal do Espírito Santo, Vitória (ES), Brazil.

*Corresponding author: raizatuao@hotmail.com

\section{BACKGROUND}

COVID-19 acute respiratory syndrome has a broad spectrum of progression and complex multisystemic involvement. Its role in autoimmune manifestations has been explored in the literature, with reports of triggers for rheumatic diseases. The association between viral infections with autoantibody production and the development of autoimmune diseases is already established. Thus, the aim of this study is to show a case of coronavirus association and subsequent diagnosis of dermatomyositis.

\section{CASE REPORT}

A 67-year-old female patient with COVID-19 infection in November 2020, confirmed by positive RT+PCR test for SARS-CoV-2, associated with symptoms such as anosmia, ageusia, fever and productive cough. She evolved in January 2021 with skin lesions on hands, face and trunk, diffuse arthralgia, dysphagia, dysphonia, asthenia and muscle weakness, becoming bedridden. We received the patient in our service after 3 months of progression. On examination, she presented erythematous-violaceous lesions on the opisthenar area of the hands, consistent with Gottron papules (Figure 1), violaceous patches on the eyelids (heliotrope), cuticle hypertrophy, periungual erythema, erythema on the back (shawl sign), facial rash, neck and anterior chest rash ( $V$ neck sign). She also presented symmetrical proximal muscle weakness of the upper and lower limbs, with manual muscle testing (MMT) of 107. Laboratory tests showed an increase of creatine phosphokinase $(\mathrm{CPK})$ eight times the reference value $(877 \mathrm{U} / \mathrm{L})$, increase of transaminases and antinuclear antibody (ANA) $>1 / 60$ dotted nuclear pattern. Electroneuromyography with myopathic process of proximal predominance and moderate intensity. Initial screening for neoplasms was negative. She was on prednisone and methotrexate when she was evaluated, with clinical improvement and a drop in CPK (25 U/L). Given the severity of the case and partial response, azathioprine and human immunoglobulin were added to the treatment.

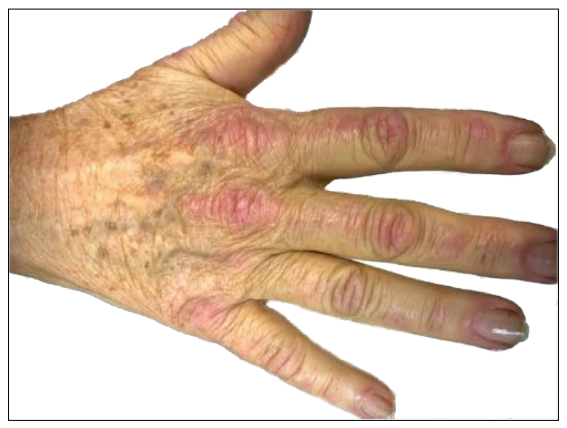

Figure 1. Gottron papules.

\section{CONCLUSION}

COVID-19 has been associated with autoimmune manifestations and several mechanisms have been proposed, including crossreaction with host cells, molecular mimicry, and epitope release. Therefore, symptoms related to muscle weakness and skin lesions in patients with active or post-infection with COVID-19 should not be underestimated and the clinical suspicion of dermatomyositis should be raised.

\section{KEYWORDS}

Dermatomyositis, Coronavirus, Muscle weakness, Rheumatic diseases. 